\title{
ALIGNMENT COUPLING DENGAN METODE DOUBLE DIAL INDICATOR RIM AND FACE
}

\author{
Ade Irvan Tauvana \\ Program Studi Teknik Mesin \\ Politeknik Enjinering Indorama \\ Email: irvan_teknikmesin@ yahoo.co.id
}

\begin{abstract}
ABSTRAK
Penelitian ini bertujuan untuk mengetahui terjadinya misalignment pada komponen trasmisi putaran dan bagaimana cara melakukan alignment yang benar serta melakukan pengujian alignment, metode yang digunakan adalah double dial indikator rim and face. Hasil penelitian pra- alignment yaitu melakukan pengecekan soft foot dengan menggunakan feeler gauge dengan data rata - rata $\mathrm{A}=0.050$ $\mathrm{mm}, \mathrm{B}=0.037 \mathrm{~mm}, \mathrm{C}=0.100 \mathrm{~mm}, \mathrm{D}=0.100 \mathrm{~mm}, \mathrm{E}=0.038 \mathrm{~mm}, \mathrm{~F}=0.025 \mathrm{~mm}, \mathrm{G}=0.113 \mathrm{~mm}$, $\mathrm{H}=0.163 \mathrm{~mm}$, pengecekan run out yang dilakukan di empat titik pada lingkaran kopling driver dengan penyetingan awal dari pada arah jam $12=0,9=0.006,6=0.031$ dan $3=0.085$, coupling offset vertikal sebesar 0,016 mm. Pengecekan run out pada kopling driven dengan titik awal pada arah jam $12=0,9=$ $0.032,6=0.107,3=0.005$, coupling offset vertikal sebesar $0,054 \mathrm{~mm}$. Setelah melakukan simulasi reposisi pada kopling driven pebaikan horizontal dan vertikal dengan perhitungan matematis rim and face maka untuk horizontal pillow block harus digeser ke kanan untuk IBdn =1,040 mm , dan OBdn =2,268 mm, Namun untuk posisi vertikal maka kaki mesin harus di tambahkan shims pada posisi IBdn $=0,688$ $\mathrm{mm}$ dan $\mathrm{OBdn}=1,522 \mathrm{~mm}$.
\end{abstract}

Kata kunci: alignment, double dial, kopling, misalignment, run out, soft foot.

\begin{abstract}
This study aims to determine the occurrence of misalignment on the spinning transition components and how to do the correct alignment and perform alignment testing, the method used is a double dial rim and face indicator. The result of pre-alignment research is to check soft foot by using feeler gauge with average data $A=0.050 \mathrm{~mm}, B=0.037 \mathrm{~mm}, C=0.100 \mathrm{~mm}, D=0.100 \mathrm{~mm}, E=0.038 \mathrm{~mm}, F=0.025 \mathrm{~mm}$, $G=0.113 \mathrm{~mm}, H=0.163 \mathrm{~mm}$, checking out runs at four points on driver clutch circle with initial setup of clockwise $12=0,9=0.006,6=0.031$ and $3=0.085$, vertical offset coupling of $0.016 \mathrm{~mm}$. Checking run out on clutch driven with starting point at clock direction $12=0,9=0.032,6=0.107,3=0.005$, vertical offset coupling of $0.054 \mathrm{~mm}$. After performing a repositioning simulation on horizontal and vertical driven coupling coupling with mathematical rim and face calculations then for horizontal pillow block should be shifted to the right for $I B d n=1.040 \mathrm{~mm}$, and $O B d n=2,268 \mathrm{~mm}$, but for vertical position then the machine foot should be added shims on position of IBdn =0,688 $\mathrm{mm}$ and $O B d n=1,522 \mathrm{~mm}$
\end{abstract}

Keywords: alignment, double dial, coupling, misalignment, run out, soft foot.

\section{PENDAHULUAN}

Industri di seluruh dunia kehilangan miliaran dollar pertahun akibat misalignment mesin. Misalignment dapat terjadi disebabkan karena mesin mengalami soft foot pada kaki-kaki mesin dan terjadi run out pada kopling dan poros mesin, yang dapat mengakibatkan terjadinya paralel misalignment dan angular misalignment. Metode kasar yang sering digunakan tidak memberikan alignment yang akurat, dengan menggunakan metode double dial indicator dapat memberikan alignment yang benar dan dapat digunakan untuk memeriksa run out pada kopling dan poros.

Mesin yang mengalami soft foot dapat diperbaiki dengan menambahkan shims pada kaki-kaki mesin yang mengalami soft foot dengan mengukur gap pada kaki-kaki mesin menggunakan feeler gauge. Mengetahui terjadinya run out pada kopling dan poros dapat dilakukan pengecekan menggunakan dial indicator yang dipasangkan pada lingkar kopling atau lingkar poros, layak atau tidaknya sesuai dengan toleransi masing-masing rpm mesin, semakin besar rpm mesin semakin kecil toleransinya. Pengecekan misalignment dapat dilakukan dengan mensimetriskan poros motor dengan poros pompa menggunakan dial indicator yang dipasang di kopling motor dengan pegangan di pompa.

Pentingnya alignment yang akurat pada mesin, diperlukan adanya alat simulasi uji alignment dengan 
menggunakan metode double dial indicator yang dapat memberikan gambaran dan pengetahuan bagaimana cara meng-alingment mesin yang mengalami paralel misalignment dan angular misalignment, begitu juga agar dapat mengetahui sebab-sebab misalignment dengan melakukan pengecekan soft foot dan pengecekan run out

Alignment adalah suatu pekerjaan yang meluruskan atau mensejajarkan dua sumbu poros hingga sentris (antara poros penggerak dengan sumbu poros yang digerakkan). Tujuan aligment untuk mendapatkan kelurusan/kesentrisan antara kedua poros pemutar (driver) dan poros yang diputar (driven) hingga tidak menimbulkan gesekan, getaran, dan lain-lain yang dapat memperpendek umur sebuah mesin yang tentunya akan menambah biaya pengeluaran untuk perbaikan maupun penggantian mesin [1].

Ketidaklurusan (misalignment) adalah Penyimpangan dari garis sumbu ke dua poros yang dipersambungkan, baik arah sejajar (parallel) maupun arah aksial (angular),sehingga terjadi ketidak sebarisan dari ke dua poros yang dipersambungkan tersebut. Soft foot adalah kepincangan yang terjadi pada kaki-kaki mesin, dimana kaki-kaki mesin tidak duduk dengan sempurna pada base plate [1].

Metode rim \&face dial-indicator digunakan sebagai standar dari alignment, keunggulannya dibanding dengan metode pengukuran yang lebih modern adalah relatif lebih sedikit, tapi jika pada kopling yang besar permukaannya mungkin masih diukur dengan metode ini. Ini juga bisa untuk memeriksa run-out (penggeseran) pada permukaan kopling yang besar dan juga merupakan prosedur praalignment [2].

Beberapa penelitian tentang alignment kopling menggunakan sinyal getaran dengan metode reverse menghasilkan kondisi misalignment puncak tertinggi diatas amplitudo $0,5 \mathrm{in} / \mathrm{s}$ dan setelah dialignment puncak tertingginya turun drastis hanya tidak sampai amplitudo 0,06 in/s [3]. alignment kopling menggunakan sinyal getaran dengan metode rim and face menghasilkan amplitudonya 0,5042 in/s [4]. Penelitian lain yaitu pembuatan dan perawatan modul alignment poros dan kopling dengan metode reverse single dial indicator. Hasil yang didapat dari pengujian sesuai dengan batas toleransi sebesar $0.5 \mathrm{~mm}$ [5]

\section{METODOLOGI PENELITIAN}

Mesin uji dan alat ukur yang digunakan dalam penelitian ini dapat dilihat seperti gambar 1 .

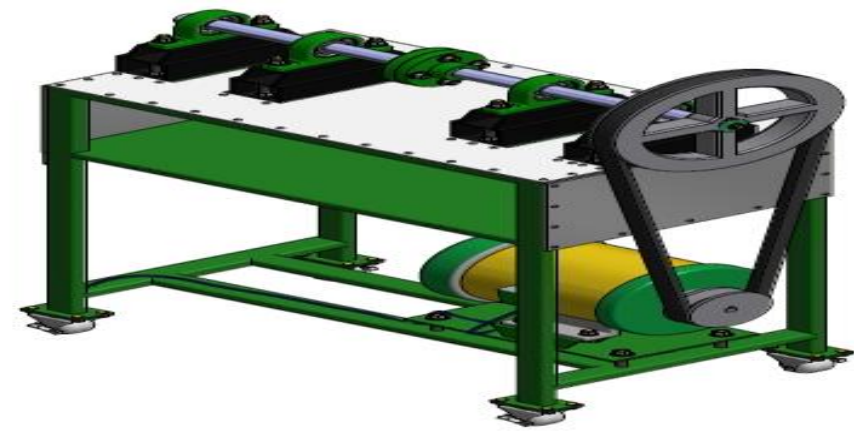

(a). Mesin uji yang digunakan

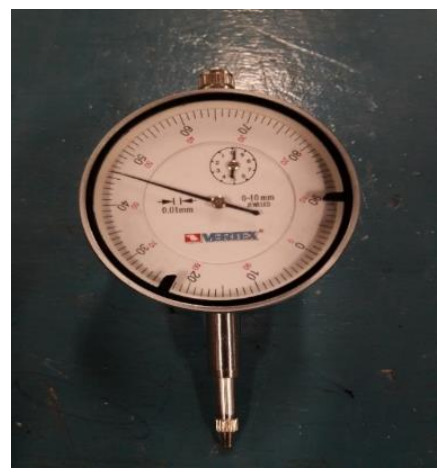

(b) Dial indicator

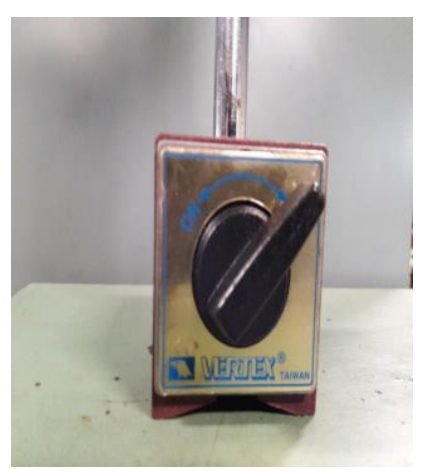

(c). Magnet base

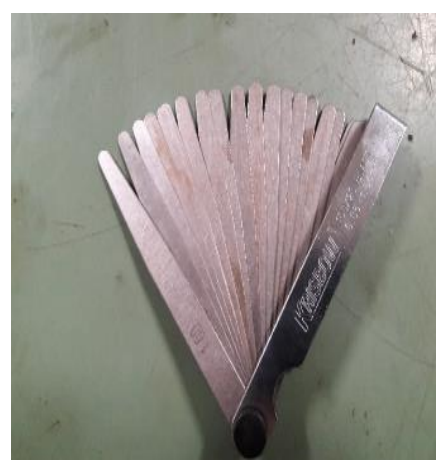

(d) Feeler gauge

Gambar 1. Mesin Uji Yang Digunakan, Alat Ukur Yang Digunakan 
Penelitian ini dilaksanakan dalam 2 tahap, yaitu :

a. Tahap Langkah Pra- Aligment Metode Alignment Rim And Face Sebelum melaksanakan alignment double dial indikator terlebih dahulu lakukan pengecekan terhadap run out poros dan kopling. Langkah pengecekan run out :

1. Pasang bracket/pemegang pada hub kopling driven

2. Jarum dial menunjuk pada hub kopling motor driver

3. Hub kopling motor dibagi mejadi 4 dan beri tanda jam $12.00,3.00$, 6.00 , 9.00 di lihat dari bagian depan motor.

4. Jarum set menyentuh hub bagian atas dan penunjukan di angka skala 0.00

5. Putar hub kopling motor, hub kopling driven tetap/dial tidak diputar.

6. Putar 360 derajat, catat setiap posisi minimal 4 posisi, yaitu jam 12.00, jam 3.00, jam 6.00, jam 9.00 .

7. Setelah kembali ke jam 12.00 jarum dial seharusnya menunjuk kembali ke angka 0 , jika tidak nol kemungkinan ada kesalahan saat memutar atau kesalahan dalam dial indicator.

8. Disarankan untuk mengambil data lebih dari satu-kali, kemudian di rata- rata.

b. Langkah pelaksanaan Pelaksanaan Metode Alignment Rim and Face

1. Pasang pemegang/bracket pada mesin atau poros pertama driven yang mudah diputar, cukup kokoh tidak goyang, supaya tidak terjadi kesalahan.

2. Pasang dial indicator ke muka (face) dan lingkaran ( rim) poros yang kedua driven.

3. Reset indicator ke posisi jam 12.

4. Putarkan poros dan bracket dengan pelan ke posisi jam 3, 6 \& 9, jika memungkinkan dan ambil pengukuran pada posisi ini (positif atau negatif).

5. Kembali ke posisi jam 12 untuk memeriksa apakah indicator mempunyai nilai 0 lagi.

6. Ulangi prosedur 1 sampai 4 untuk memeriksa ulang pengukuran pada pengambilan data pertama.

7. Untuk mendapatkan hasil yang lebih teliti, pengukuran harus dilakukan 2 s/d 4 kali, kemudian di rata-rata.

8. Pasang konektor ke arus listrik yang sesuai dengan tegangan motor

9. Nyalakan alat simulasi kelurusan poros / kopling dengan menekan saklar on.

10. Lihat running alat setelah proses alignment dilakukan

\section{HASIL DAN PEMBAHASAN}

3.1 Pembahasan Data, Hasil Pra- Aligment Metode Alignment Rim and Face

Tabel 1. Hasil pengambilan data run out pada kopling driver

\begin{tabular}{ccccc}
\hline \multirow{2}{*}{ No } & \multicolumn{4}{c}{ Posisi pengambilan data run out (mm) } \\
\cline { 2 - 5 } & Arah jam 12 & Arah jam 9 & Arah jam 6 & Arah jam 3 \\
\hline 1 & 0 & 0.010 & 0.050 & 0.020 \\
2 & 0 & 0.005 & 0.045 & 0.015 \\
3 & 0 & 0.005 & 0.010 & 0.010 \\
4 & 0 & 0.005 & 0.020 & 0.040 \\
\hline Rata -rata & $\mathbf{0}$ & $\mathbf{0 . 0 0 6}$ & $\mathbf{0 . 0 3 1}$ & $\mathbf{0 . 0 8 5}$ \\
\hline
\end{tabular}

Hasil pengecekan run out yang dilakukan di empat titik pada lingkaran kopling driver dengan penyetingan awal dapat dilihat pada tabel 1 dari pada arah jam $12=0,9=0.006,6=0.031$ dan $3=0.085$ maka toleransi alignment dengan acuan putaran kopling tersebut dikatakan aman serta masih bagus karena putaran yang di trasmisikan $=473 \mathrm{rpm}$ dengan toleransi excellent $4.0 \mathrm{~mm}$, hasil dari perbandingan pulley 1:3 dengan rpm motor 1420 .

Pengecekan run out ini sebagai acuan untuk pra-alignment supaya alignment mendapat hasil yang lebih baik, jika sudah mengetahui masalah penyimpangan pada kopling yang nantinya akan dilakukan metode kesejajaran kopling (alignment). Mengelola data vertikal misalignment DIR dari data diatas arah jam 12 dan jam 6 dengan nilai rata - rata $=0.031$, maka hitung dengan persamaan :

Coupling offset $=\frac{\text { RIM dial (DIR) TIR }}{2}=\frac{0,031}{2}=0,016 \mathrm{~mm}$

Berdasarkan persamaan 1 maka besarnya perbaikan coupling offset vertikal sebesar 0,016 mm 
Tabel 2. Hasil pengambilan data run out pada kopling driven

\begin{tabular}{ccccc}
\hline \multirow{2}{*}{ No } & \multicolumn{4}{c}{ Posisi pengambilan data run out $(\mathrm{mm})$} \\
\cline { 2 - 5 } & Arah jam 12 & Arah jam 9 & Arah jam 6 & Arah jam 3 \\
\hline 1 & 0 & 0.001 & 0.003 & 0 \\
2 & $\mathbf{0}$ & $\mathbf{0 . 1 2 0}$ & $\mathbf{0 . 2 4 0}$ & $\mathbf{0 . 0 1 5}$ \\
3 & 0 & 0.003 & 0.100 & 0.005 \\
4 & 0 & 0.003 & 0.085 & 0 \\
\hline Rata -rata & $\mathbf{0}$ & $\mathbf{0 . 0 3 2}$ & $\mathbf{0 . 1 0 7}$ & $\mathbf{0 . 0 0 5}$ \\
\hline
\end{tabular}

Hasil pengecekan run out pada kopling driven dapat dilihat pada tabel 2 dengan titik awal pada arah jam $12=0,9=0.032,6=0.107,3=0.005$ masih termasuk dalam toleransi dan dikatan bagus. Dari hasil rata - rata arah jam 12 dan jan 6 di atas $=0.107$, maka dilakukan perbaikan vertikal misalignment dengan persamaan 1 : Coupling offset

$$
\mathrm{t}=\frac{\mathrm{RIM} \operatorname{dial}(\mathrm{DIR}) \mathrm{TIR}}{2}=\frac{0,107}{2}=0,054 \mathrm{~mm}
$$

Tabel 3. Hasil pengambilan data run out pada poros driver

\begin{tabular}{ccccc}
\hline \multirow{2}{*}{ No } & \multicolumn{4}{c}{$\begin{array}{c}\text { Posisi pengambilan data run out } \\
(\mathbf{m m})\end{array}$} \\
\cline { 2 - 5 } & Arah jam 12 & Arah jam 9 & Arah jam 6 & Arah jam 3 \\
\hline 1 & 0 & 0.005 & 0.010 & 0.010 \\
2 & 0 & 0.005 & 0.005 & 0 \\
3 & 0 & 0.005 & 0.009 & 0 \\
4 & 0 & 0 & 0.002 & 0.008 \\
\hline Rata -rata & $\mathbf{0}$ & $\mathbf{0 . 0 0 4}$ & $\mathbf{0 . 0 0 7}$ & $\mathbf{0 . 0 0 5}$ \\
\hline
\end{tabular}

Hasil pengecekan run out pada poros driver sesuai tabel 3 dengan penyetingan awal dial indicator pada arah jam 12 hasilnya masih dalam toleransi yang diijinkan serta poros dikatakan bagus.

Tabel 4. Hasil pengambilan data run out pada poros driven

\begin{tabular}{ccccc}
\hline \multirow{2}{*}{ No } & \multicolumn{4}{c}{$\begin{array}{c}\text { Posisi pengambilan data run out } \\
(\mathbf{m m})\end{array}$} \\
\cline { 2 - 5 } & Arah jam 12 & Arah jam 9 & Arah jam 6 & Arah jam 3 \\
\hline 1 & 0 & 0.005 & 0.002 & 0.009 \\
2 & 0 & 0.020 & 0.030 & 0.050 \\
3 & 0 & 0.030 & 0.020 & 0.040 \\
4 & 0 & 0.020 & 0.018 & 0.040 \\
\hline Rata -rata & $\mathbf{0}$ & $\mathbf{0 . 0 1 9}$ & $\mathbf{0 . 0 2 0}$ & 0.040 \\
\hline
\end{tabular}

Hasil pengecekan run out pada poros driven pada tabel 4 masih dikatakan bagus karena masih dibawah toleransi yang diijinkan tabel 4 dengan acuan putaran. Langkah pengecekan soft foot dapat dilihat pada gambar 2. Cek gap kaki kaki pada posisi 1, 2, 3, 4 terhadap pondasi/unp dengan menggunakan feeler gauge dan catat hasil penyimpangan tersebut.

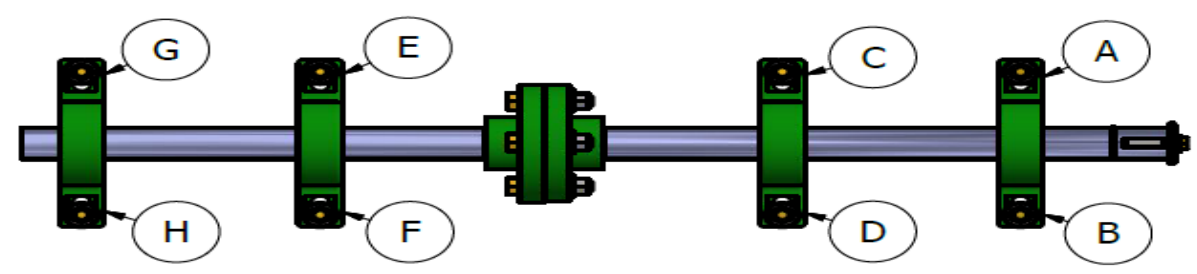

Gambar 2. Posisi Kaki Pillow Block Horizontal Menggunakan Feeler Gauge 
Tabel 5. Hasil pengukuran gap kaki pillow block menggunakan feeler gauge

\begin{tabular}{cccccc}
\hline \multirow{2}{*}{$\begin{array}{c}\text { Bagian kaki } \\
\text { pillow block }\end{array}$} & $\mathbf{1}(\mathbf{m m})$ & $\mathbf{2 ( \boldsymbol { m m } )}$ & $\mathbf{3}(\mathbf{m m})$ & $\mathbf{4}(\mathbf{m m})$ & $\begin{array}{c}\text { Rata }- \text { rata } \\
(\mathbf{m m})\end{array}$ \\
\cline { 2 - 5 } A & 0.050 & 0.050 & 0.050 & 0.050 & 0.050 \\
B & 0.050 & 0.100 & 0 & 0 & 0.037 \\
C & 0.150 & 0.150 & 0.050 & 0.050 & 0.100 \\
D & 0.150 & 0.150 & 0.050 & 0.050 & 0.100 \\
E & 0.100 & 0.050 & 0 & 0 & 0.038 \\
F & 0 & 0.050 & 0 & 0.050 & 0.025 \\
G & 0.300 & 0.150 & 0 & 0 & 0.113 \\
H & 0.500 & 0 & 0.150 & 0 & 0.163 \\
\hline
\end{tabular}

Pengecekan soft foot dilakukan untuk penyetaraan kaki mesin / pillow block supaya semua kaki mesin / pillow block dapat menempel secara merata, dari hasil pengecekan sesuai tabel 5 maka semua kaki mesin yang mendapat penyimpangan besar dipasang shims supaya hasil alignment dapat lebih akurat [6].

Tabel 6. Hasil pengukuran soft foot pada kaki pillow block menggunakan dial

\begin{tabular}{cccccc}
\hline \multirow{2}{*}{$\begin{array}{c}\text { Bagian } \text { kaki } \\
\text { pillow block }\end{array}$} & $\mathbf{1}(\mathbf{m m})$ & $\mathbf{2 ( \boldsymbol { m m } )}$ & $\mathbf{3}(\mathbf{m m})$ & $\mathbf{4}(\mathbf{m m})$ & $\begin{array}{c}\text { Rata }- \text { rata } \\
(\mathbf{m m})\end{array}$ \\
\cline { 2 - 5 } A & 0.003 & 0.003 & 0.003 & 0.003 & 0.003 \\
B & 0.002 & 0.002 & 0.002 & 0.002 & 0.002 \\
C & 0.015 & 0.015 & 0.015 & 0.015 & 0.015 \\
D & 0.050 & 0.050 & 0.050 & 0.050 & 0.050 \\
E & 0.003 & 0.003 & 0.003 & 0.003 & 0.003 \\
F & 0.003 & 0.003 & 0.003 & 0.003 & 0.003 \\
G & 0.020 & 0.020 & 0.020 & 0.020 & 0.020 \\
H & 0.001 & 0.001 & 0.001 & 0.001 & 0.001 \\
\hline
\end{tabular}

Hasil dari pengecekan soft foot dengan dial indicator sesuai tabel 6 dilakukan 4 posisi pengecekan setiap kaki motor / pillow block dan diambil rata - rata, hasil rata - rata tersebut adalah nilai kaki motor / pillow block yang mengalami per setelah ditambah shims $0.02 \mathrm{~mm}$, namun nilai rata rata tersebut masih sangat kecil maka shims tidak perlu dirubah kembali memakai shims yang lebih besar.

\subsection{Pembahasan Data, Hasil dan Pelaksanaan Metode Alignment Rim and Face}

Data hasil hasil pengukuran kasar dengan penggaris dilanjut dengan dial indikator dicatat dalam bentuk tabel sebagai berikut :

Tabel 7. Hasil alignment kopling driver

\begin{tabular}{|c|c|c|c|c|c|c|}
\hline \multirow{3}{*}{$\begin{array}{c}\text { Jumlah } \\
\text { pengujian }\end{array}$} & \multicolumn{6}{|c|}{$\begin{array}{l}\text { Posisi pengukuran diputar searah jarum jam } \\
\text { (mm) }\end{array}$} \\
\hline & \multicolumn{2}{|c|}{ Arah jam 12} & \multicolumn{2}{|c|}{ Arah jam 9} & \multicolumn{2}{|c|}{ Arah jam 3} \\
\hline & $\operatorname{Rim}$ & Face & Rim & Face & $\operatorname{Rim}$ & Face \\
\hline 1 & 0 & 0 & 0 & 0.250 & 0 & 0.100 \\
\hline 2 & 0 & 0 & 0.002 & 0.020 & 0 & 0.100 \\
\hline 3 & 0 & 0 & 0.003 & 0.100 & 0 & 0.180 \\
\hline 4 & 0 & 0 & 0.004 & 0.120 & 0.020 & 0.200 \\
\hline 5 & 0 & 0 & 0.005 & 0.220 & 0 & 0.100 \\
\hline Rata - rata & 0 & 0 & 0.002 & 0.198 & 0.004 & 0.136 \\
\hline
\end{tabular}

Data hasil pengecekan / pengambilan data pada kopling driver sesuai tabel 7 dengan hasil rata - rata masih sangat kecil dibawah toleransi alignment yang diijinkan, maka kopling dinyatakan masih dalam kondisi baik serta tidak perlu perbaikan alignment / reposisi ulang. 
Tabel 8. Hasil alignment kopling driven

\begin{tabular}{|c|c|c|c|c|c|c|}
\hline \multirow{3}{*}{$\begin{array}{c}\text { Jumlah } \\
\text { pengujian }\end{array}$} & \multicolumn{6}{|c|}{$\begin{array}{c}\text { Posisi pengukuran diputar searah jarum jam } \\
(\mathrm{mm})\end{array}$} \\
\hline & \multicolumn{2}{|c|}{ Arah jam 12} & \multirow{2}{*}{\multicolumn{2}{|c|}{ Arah jam 9}} & \multicolumn{2}{|c|}{ Arah jam 3} \\
\hline & Rim & Face & $\operatorname{Rim}$ & & Rim & Face \\
\hline 1 & 0 & 0 & 0.050 & 0.220 & 0.300 & 0.400 \\
\hline 2 & 0 & 0 & 0.030 & 0.230 & 0.250 & 0.300 \\
\hline 3 & 0 & 0 & 0 & 0.150 & 0.210 & 0.200 \\
\hline 4 & 0 & 0 & 0 & 0.210 & 0.300 & 0.300 \\
\hline 5 & 0 & 0 & 0 & 0.200 & 0.260 & 0.400 \\
\hline Rata - rata & 0 & 0 & 0.016 & 0.202 & 0.264 & 0.320 \\
\hline
\end{tabular}

Hasil pengukuran kopling driver dan driven menurut tabel 8 penyimpangannya masih termasuk toleransi . Namun untuk memperkecil nilai yang didapat dari rata - rata di atas maka perlu di lakukan reposisi pada salah satu bagian trasmisi kopling tersebut.

Sebagai contoh melakukan simulasi reposisi pada kopling driven Maka yang di ambil tabel hasil pengambilan data run out pada kopling driven untuk arah horizontal dan tabel hasil alignment kopling driven untuk arah vertical dengan nilai yang tertinggi dari hasil pengecekan, Serta perlu dilakukan reposisi dengan cara perhitungan matematis rim and face sebagai berikut.

Diketahui ;

a. Vertikal

$$
\begin{aligned}
& \operatorname{Rim}(\text { radial }) F=0.240+0=0.240 \mathrm{~mm} \\
& \left(\text { aksial) } Y=\frac{(0.120+0.015)}{2}=0.185 \mathrm{~mm}\right.
\end{aligned}
$$

b. Horizontal

$$
\begin{aligned}
& \operatorname{Rim}(\text { radial }) F=0.050+0.300=0.350 \mathrm{~mm} \\
& \text { Face (aksial) } Y=\frac{(0.220+0.400)}{2}=0.320 \mathrm{~mm}
\end{aligned}
$$

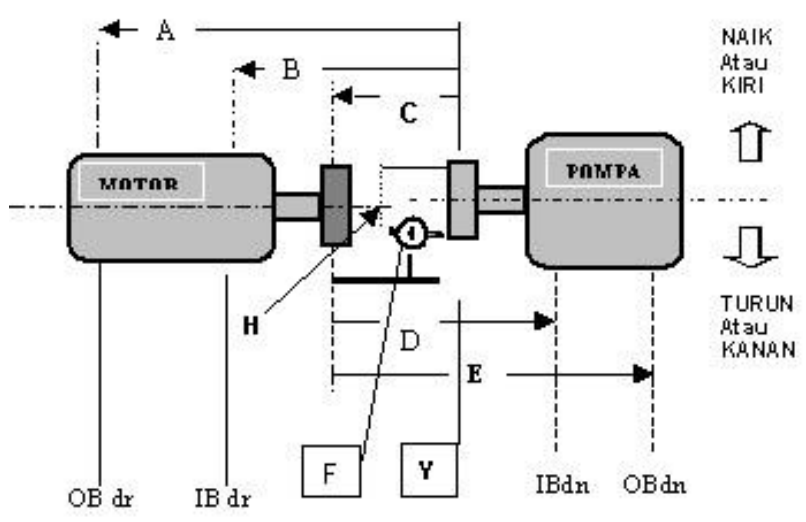

\section{Gambar 3. Sketsa pengaplikasian formula matematis}

Gambar sketsa dapat ditunjukkan pada gambar 3

A : $295 \mathrm{~mm}$ jarak dari titik pengukuran dial indicator di hub kopling driven ke kaki driver OBdr (outboard).

$\mathrm{B}=120 \mathrm{~mm}$ jarak dari titik pengukuran dial indicator di hub kopling driven ke kaki driver IBdn (inboard).

$\mathrm{C}=15$ lebar kopling rim yang di titik plunjer dila di letakan+gap 0.20 diukur memaki fleer gauge.

$\mathrm{D}=120 \mathrm{~mm}$ jarak dari titik pengukuran dial indikator di hub kopling driver ke kaki driven IBdn (inboard)

$\mathrm{E}=295$ mm karena jarak antara kaki - kaki pillow block driven sama driver sama, maka jarak dari titik pengukuran dial indicator di hub kopling driver ke kaki driven OBdn (outboard)

$\mathrm{H}=50$ diameter hub kopling (di ukur dari lintasan yang dilewati dial indikator)

Karena dial melintas setengah diameter kopling $100 \mathrm{~mm}$ maka di hasilkan $50 \mathrm{~mm}$. 
Reposisi dengan perhitungan matematis

a. Vertikal

$$
\begin{aligned}
& \mathrm{IBdn}=\frac{F[(B)-(C)}{\sqrt{H^{2}-F^{2}}}+Y \\
& \mathrm{IBdn}=\frac{0,240[(120)-(15.2)}{\sqrt{50^{2}-0,240^{2}}}+0,185=0.688 \mathrm{~mm} \\
& \text { OBdn }=\frac{F[(E)-(C)]}{\sqrt{H^{2}-F^{2}}+(Y)} \\
& \text { OB dn }=\frac{0,240[(295)-(15,2)}{\sqrt{50^{2}-0,240^{2}}}+0,185=1,522 \mathrm{~mm}
\end{aligned}
$$

b. Horizontal

$$
\begin{aligned}
& \mathrm{IBdn}=\frac{F[(D)-(C)]}{\sqrt{H^{2}-F^{2}}+(Y)} \\
& \mathrm{IBdn}=\frac{0,350[(120)-(15,2)]}{\sqrt{50^{2}-0,350^{2}}}+0,310=1,043 \mathrm{~mm} \\
& \text { OBdn }=\frac{F[(E)-(C)]}{\sqrt{H^{2}-F^{2}}+(Y)} \\
& \text { OB dn }=\frac{0,350[(295)-(15,2)]}{\sqrt{50^{2}-0.350^{2}}}+0,310=\frac{73,02}{49,99}+0,310=2,268 \mathrm{~mm}
\end{aligned}
$$

Untuk Vertikal reposisi driven:

a. Berdasarkan persamaan 2 maka nilai IBdn (inboard driven = kaki dalam driven) menambah shim $=0,688 \mathrm{~mm}$

b. Berdasarkan persamaan 3 OBdn (outboard driven $=$ kaki luar driven) menambah shim $=1,522$ $\mathrm{mm}$

Selanjutnya horizontal reposisi driven sebagai berikut:

a. Berdasarkan persamaan 4 diperoleh nilai IBdn (inboard driven) menggeser kekanan =1,040 $\mathrm{mm}$

b. Berdasarkan persamaan 5 diperoleh nilai OBdn (outboard driven) menggeser kekanan =2,268 $\mathrm{mm}$

\section{KESIMPULAN}

Sebelum melakukan proses alignment makan terlebih dahulu lakukan pra- alignment yaitu melakukan pengecekan soft foot d dengan menggunakan feeler gauge dengan data rata - rata $\mathrm{A}=0.050$ $\mathrm{mm}, \mathrm{B}=0.037 \mathrm{~mm}, \mathrm{C}=0.100 \mathrm{~mm}, \mathrm{D}=0.100 \mathrm{~mm}, \mathrm{E}=0.038 \mathrm{~mm}, \mathrm{~F}=0.025 \mathrm{~mm}, \mathrm{G}=0.113 \mathrm{~mm}$, $\mathrm{H}=0.163 \mathrm{~mm}$, pengecekan run out yang dilakukan di empat titik pada lingkaran kopling driver dengan penyetingan awal dari pada arah jam $12=0,9=0.006,6=0.031$ dan $3=0.085$, coupling offset vertikal sebesar 0,016 mm. Pengecekan run out pada kopling driven dengan titik awal pada arah jam $12=0,9=$ $0.032,6=0.107,3=0.005$, coupling offset vertikal sebesar $0,054 \mathrm{~mm}$. Setelah melakukan simulasi reposisi pada kopling driven pebaikan horizontal dan vertikal dengan perhitungan matematis rim and face sesuai tabel 7 dan tabel 8 maka untuk horizontal pillow block harus digeser ke kanan untuk IBdn $=1,040$ $\mathrm{mm}$, dan $\mathrm{OBdn}=2,268 \mathrm{~mm}$, Namun untuk posisi vertikal maka kaki mesin harus di tambahkan shims pada posisi $\mathrm{IBdn}=0,688 \mathrm{~mm}$ dan $\mathrm{OBdn}=1,522 \mathrm{~mm}$.

\section{DAFTAR PUSTAKA}

[1] Sidharta, Linmas. 2012. Paper Alignment-Soft Foot Correction.LNG academy : Jakarta.

[2] Hidayat. Raffi. 2011. Balancing and Alignment. PT PLN (Persero) Pusdiklat Suralaya

[3] Dwi Deni, Widodo A.Haryanto I, 2016, Misalignment Kopling Dengan Analisis Sinyal Getaran 
Kondisi Steady State Menggunakan Metode Reverse, JTM Vol. 4 hal. 196-206.Universitas DiponegoroSemarang.

[4] Agus Iman, Widodo A.Haryanto I, 2016, Misalignment Kopling Dengan Analisis Sinyal Getaran Kondisi Steady State Menggunakan Metode Rim And Face, JTM Vol. 4 hal. 214-233. Universitas Diponegoro Semarang.

[5] Rojali .J , 2016, Pembuatan Dan Perawatan Modul Alignment Poros Dan Kopling Dengan Metode Reverse Single Dial Indicator. Politeknik Enjinering Indorama Purwakarta.

[6] Sharul. M, 2016, Improvement On Pump Footing System For Misalignment Correction. Universiti Teknikal Malaysia Melaka. 